\title{
Spectroscopy: The uniting tool for interdisciplinary research, from art to the history and structure of the universe
}

\author{
Parvez I. Haris \\ Faculty of Health \& Life Sciences, De Montfort University, The Gateway, Leicester, LE1 9BH, UK \\ E-mail: pharis@dmu.ac.uk
}

There is no doubt that spectroscopy is one of few tools that can bring together researchers from fields as diverse as art, archaeology, astronomy, biology, botany, chemistry, dentistry, computer science, engineering, environmental science, forensics, geology, hydrology, history, mathematics, medicine, nutrition, pharmacy, physics, psychology, sociology, zoology and so on. Apologies for not mentioning each and every discipline! Indeed, it is difficult to imagine a field of research activity where spectroscopy cannot play a role. Spectroscopy has been at the centre of research from searching for water on mars [4] to identifying the life-style of King Richard III of England, whose body was lost for more than 500 years, and eventually found under a car park in Leicester [5]. These are only few examples of how researchers from diverse fields work together to solve problems with spectroscopy often playing a pivotal role. There is little doubt that spectroscopy can be a tool that can unite researchers who otherwise may have few reasons to cross paths, let alone collaborate.

The need to encourage and support interdisciplinary research is being made loud and clear by leading authorities in different fields of research. For example, Nobel Laureate Sir Paul Nurse FRS (Fig. 1) produced a report on the UK research councils where he stressed the importance of supporting interdisciplinary research [3]. The fact that he is a strong supporter of interdisciplinary research became clearer when I had the opportunity to engage in discussions with him when he came to present a lecture at my University and also officially open my interdisciplinary research laboratory (see Fig. 1).

I write this editorial during a particularly sad period when two of the greatest British scientists have left us, namely Nobel laureate Sir John Sulston FRS and Professor Stephen Hawking FRS. Sir John Sulston FRS will be best remembered for his work on the decoding of the human genome and for his dedication to keeping scientific data freely accessible to the public. He died of stomach cancer on the 6th of March 2018 in Cambridge at the age of 75. Few days later, on the 14th of March, Professor Stephen Hawking FRS who dedicated his life to unlock the secrets of the universe, passed away also in Cambridge at the age of 76. Professor Hawking is a strong supporter of interdisciplinary research. In October 2016, he opened the Leverhulme Centre for the Future of Intelligence [1]. This centre brings together scientists from leading Universities in the UK and USA to engage in cutting edge interdisciplinary research aimed at addressing challenging questions related to artificial intelligence and its impacts. Not only in Europe and USA, but throughout the world, there is a growing acceptance that real progress in finding answers to the challenges that face human beings requires researchers from different disciplines to work together. For example, Tsinghua University in China launched the Tsinghua Laboratory of Brain and Intelligence 


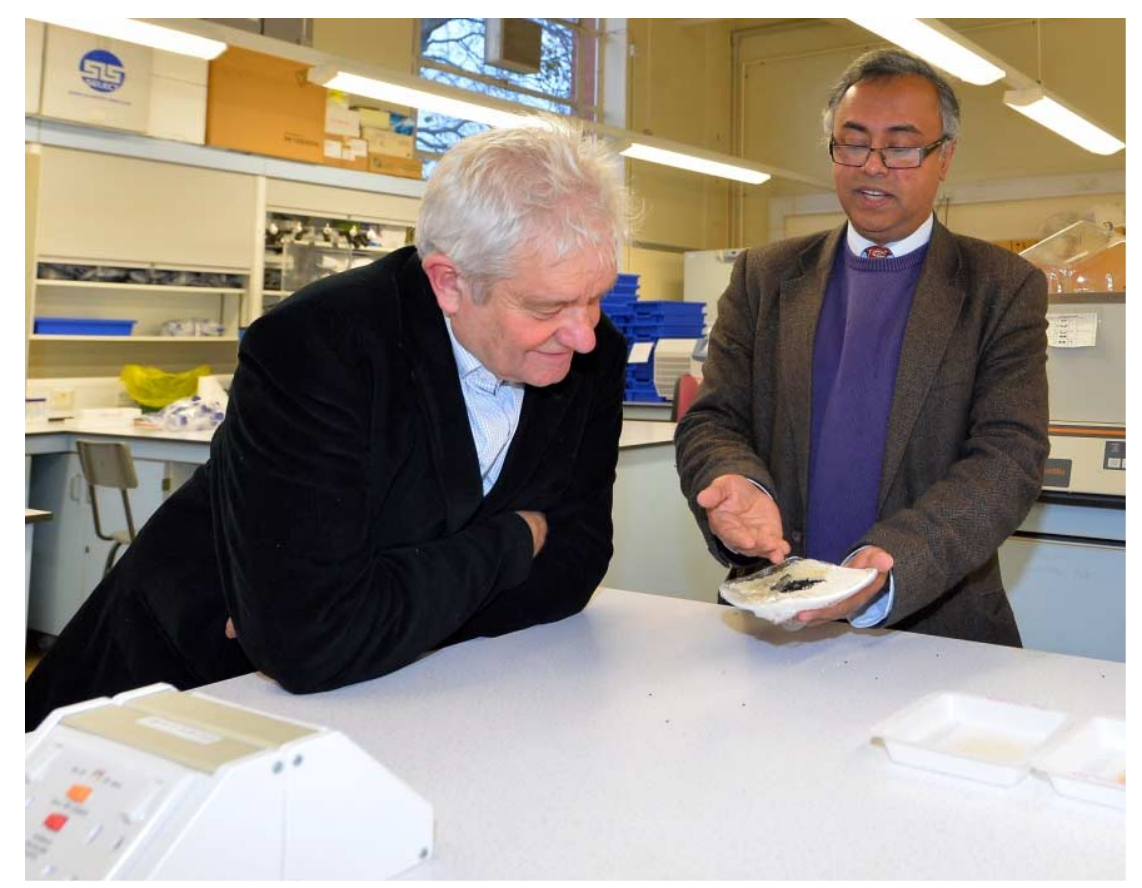

Fig. 1. Nobel laureate, Sir Paul Nurse FRS (left), with the author of this article (6 December 2017). Sir Paul Nurse is looking at Bangladeshi aromatic rice (Kalijeera, considered to be the smallest rice in the world) and Nigella sativa seeds (known as Kalijeera in Bengali and after which the Kailjeera variety of Bangladeshi aromatic rice is named). Sir Paul Nurse officially opened the Laboratory of Biomedical and Environmental Health Research which carries out interdisciplinary research with spectroscopic techniques playing a central role. Photo credit: Alex Hannam.

(THBI) and the Future Laboratory which are aimed at boosting interdisciplinary research [2]. These are exciting times for researchers around the world, especially spectroscopists as their tool is perhaps best placed to take advantage of these new developments by engaging with researchers from fields that may appear to be very different from their own.

The current issue of Biomedical Spectroscopy and Imaging contains several good articles where spectroscopic techniques have played a central role in interdisciplinary research.

This issue also contains several articles associated with the 17th European Conference on the Spectroscopy of Biological Molecules that was held in Amsterdam in September 2017. I would like to thank Proferssor Marloes Groot who organised the conference. Both of us co-ordinated the conference proceedings that are published in this issue of Biomedical Spectroscopy \& Imaging.

\section{References}

[1] http://www.cam.ac.uk/research/news/the-best-or-worst-thing-to-happen-to-humanity-stephen-hawking-launches-centrefor-the-future-of (last accessed 29 March 2018).

[2] http://goglobal.tsinghua.edu.cn/en/news/news.en/gryw8WK2e (last accessed 29 March 2018).

[3] https://www.gov.uk/government/publications/nurse-review-of-research-councils-recommendations (last accessed 29 March 2018).

[4] T. Encrenaz, T.K. Greathouse, B. Bézard, T. Fouchet, F. Lefèvre, F. Montmessin, M. Bitner, A. Kruger, M.J. Richter, J.H. Lacy and F. Forget, Water vapor map of Mars near summer solstice using ground-based infrared spectroscopy, Astronomy \& Astrophysics 520 (2010), A33. doi:10.1051/0004-6361/200913905.

[5] A.L. Lamb, J.E. Evans, R. Buckley and J. Appleby, Multi-isotope analysis demonstrates significant lifestyle changes in King Richard III, Journal of Archaeological Science 50 (2014), 559-565. doi:10.1016/j.jas.2014.06.021. 